\title{
Perianal Crohn's disease and hidradenitis suppurativa: a possible common immunological scenario
}

\author{
Francesco Giudici ${ }^{1}$, Laura Maggi ${ }^{2}$, Raffaella Santi ${ }^{1}$, Lorenzo Cosmi ${ }^{2}$, Cristina Scaletti ${ }^{2}$, Francesco Annunziato ${ }^{2}$, \\ Gabriella Nesi ${ }^{1}$, Giusi Barra ${ }^{3}$, Gabrio Bassotti ${ }^{4}$, Raffaele De Palma ${ }^{3}$ and Francesco Tonelli ${ }^{1 *}$
}

\begin{abstract}
Background: Crohn's disease (CD) and Hidradenitis suppurativa (HS) are both chronic inflammatory diseases. The pathogenesis of these diseases is multifactorial, due to the interaction of genetic and environmental factors leading to a deregulated local immune response where T lymphocytes play a major role. To the best of our knowledge, no previous study has clarified whether the pathogenetic mechanism of perianal CD and HS is the same. We therefore analyzed the cellular expression pattern and the cytokine repertoire in three patients suffering from both perianal CD and HS.

Methods: We evaluated three patients affected by concurrent HS and CD with fistulizing perianal disease. Surgical specimens have been fixed and embedded in paraffin prior to sectioning for histological examination. Inflammatory tissue curettages have been recovered during intervention from perianal fistulas and HS lesions in order to analyze the phenotypic and functional characteristics of infiltrating T cells. In particular we evaluated T cells, by flow cytometry, for cytokine production profile and expression of surface markers. Moreover, analysis of the T cell repertoire was performed by means of spectratyping, in only one patient.
\end{abstract}

Results: A higher frequency of CD4+ CD161+ T lymphocytes has been detected in CD fistulas and in HS lesions than in peripheral blood (PB) samples. In the patient in whom we derived enough cells from the three sources, we found higher frequency of CD4+ IL-17- producing cells in HS lesion and fistula lesion compared to PB. It is noteworthy that the same clonotypes were expanded in this patient in T cells derived from both HS lesion and fistula lesion.

Conclusion: The presence of numerous CD4+ CD161+ lymphocytes in fistula and HS lesion curettages suggests that these cells may play a pathogenic role, and candidates CD161 as a possible biological target for medical treatment.

Keywords: Hidradenitis suppurativa, Crohn's disease, T helper lymphocytes

\section{Background}

Crohn's disease (CD) and hidradenitis suppurativa (HS) are chronic inflammatory diseases. HS involves the hair follicles in apocrine glandular zones, affecting the axillae, groins, external genitals or perianal regions. It is characterized by recurrent, spontaneously draining, suppurative lesions and long-lasting subcutaneous sinus tracts, cutaneous fistulae or dermal-cutaneous scars [1].

The prevalence of HS is approximately 1 in 300 and typically commences during puberty and the teenage years,

\footnotetext{
* Correspondence: francesco.tonelli@unifi.it

'Department of Surgery and Translational Medicine, University of Florence, Florence, Italy

Full list of author information is available at the end of the article
}

more frequently in females. Familial history is documented in a quarter of the patients with an autosomal inheritance [1].

CD may involve any part of the gastrointestinal tract and is defined by the presence of discontinuous, transmural, inflammatory lesions [2]. Abdominal pain and weight loss are the typical presenting symptoms. $\mathrm{CD}$ can be divided into three forms: inflammatory, fistulizing or obstructive. Between $60 \%$ and $80 \%$ of CD patients suffer from perianal fistulas $[3,4]$. Previous reports have suggested a possible association between CD and HS (Table 1) [5-16].

Although smoking is regarded as a risk factor of both $\mathrm{CD}$ and HS recurrence, the etiology of these diseases is still largely unknown and is likely to be multifactorial. It 
Table 1 Association between CD and HS as reported in the literature $(H S-C D=$ diagnosis of $H S$ predated that of $\mathrm{CD}$; CD-HS = diagnosis of CD predated that of HS)

\begin{tabular}{|c|c|c|c|c|}
\hline Author & Year & $\mathrm{N}^{\circ}$ patients & Sex & Sequence \\
\hline LS Ostlere & 1991 & 3 & $F, F, M$ & $\begin{array}{l}\text { CD-HS, CD-HS, } \\
\text { CD-HS }\end{array}$ \\
\hline C Gower-Rousseau & 1992 & 3 & M & $\begin{array}{l}\text { CD-HS, CD-HS, } \\
\text { CD-HS }\end{array}$ \\
\hline NP Burrows & 1992 & 2 & $M, F$ & $\mathrm{HS}-\mathrm{CD}, \mathrm{HS}-\mathrm{CD}$ \\
\hline RL Attanoos & 1993 & 3 & $\mathrm{~F}, \mathrm{M}, \mathrm{M}$ & $\begin{array}{l}\text { CD-HS, HS-CD, } \\
\text { CD-HS }\end{array}$ \\
\hline AA Kafity & 1993 & 1 & M & $\mathrm{CD}-\mathrm{HS}$ \\
\hline JM Church & 1993 & 61 & Both & Multiple \\
\hline EV Tsianos & 1995 & 1 & M & $\mathrm{CD}-\mathrm{HS}$ \\
\hline MK Roy & 1997 & 1 & M & HS-CD \\
\hline F Martinez & 2001 & 1 & $\mathrm{~F}$ & $\mathrm{CD}-\mathrm{HS}$ \\
\hline M Roussomoustakaki & 2003 & 1 & $\mathrm{~F}$ & HS-CD \\
\hline HH Van der Zee & 2009 & 102 & Both & Multiple \\
\hline S Yazdanyar & 2010 & 2 & $F, F$ & HS-CD, HS-CD \\
\hline
\end{tabular}

is hypothesized that genetic and environmental factors may cooperate in leading to a deregulated local immune response where $\mathrm{T}$ lymphocytes play a major role $[1,17]$. CD4+ T helper (Th) cells can be divided into different subsets according to their cytokine production profile: Th1 cells produce interferon (IFN)- $\gamma$, thus protecting against intracellular pathogens, Th2 cells produce interleukins (IL)-4, IL-5, IL-9 and IL-13 and offer defence against parasitic helminths, while Th17 cells produce IL17 and protect from fungal infections [18]. In addition to their protective role against pathogens, Th lymphocytes also contribute to the development of immunemediated disorders: in particular both Th1 and Th17 cells have been credited to being involved in inducing and maintaining an intestinal inflammatory reaction in experimental animal models as well as in human CD $[18,19]$. Furthermore, biological therapy targeting tumor necrosis factor (TNF)- $\alpha$ with specific monoclonal antibodies, has shown to be particularly effective in both CD and HS treatment [1,6,17]. Recently, local injection of anti-TNF- $\alpha$ antibodies $(\mathrm{Ab})$ has proved to be a safe and effective therapy for perianal fistulas in $\mathrm{CD}[4,20]$.

We recently observed three $\mathrm{CD}$ patients with perianal fistulas and suffering from HS, who gave us the opportunity to compare the cellular and cytokine expression profile of these lesions.

\section{Methods}

Between February and October 2011, we operated three patients affected by concurrent HS and CD with fistulizing perianal disease. Surgical treatment consisted in resection of the HS lesion, followed by fistulotomy $(\mathrm{n}=1)$ or fistulectomy $(n=2)$. Surgical specimens were fixed in $10 \%$ neutral buffered formalin and embedded in paraffin prior to sectioning for histological examination. Inflammatory tissue curettages were recovered during intervention from perianal fistulas and HS lesions in order to analyze the phenotypic and functional characteristics of the infiltrating $\mathrm{T}$ cells. These features were then compared with those of peripheral blood T lymphocytes.

To isolate $\mathrm{T}$ lymphocytes, tissue fragments were mechanically disrupted with a MEDI machine (Becton Dickinson). Fluorochrome-conjugated $\mathrm{mAbs}$ and isotype-matched control mAbs were purchased from BD Biosciences (San Jose, $\mathrm{CA})$. The fluorochrome-conjugated anti-IL-17 mAbs was obtained from eBioscience (San Diego, CA). PMA, ionomycin and brefeldin A were purchased from Sigma Chemical Co. (St. Louis, MO). Mononuclear cells (MNCs) from the different tissues were analyzed for intracellular cytokine production as previously described [18]. All procedures in the study are in accordance with the ethical standards of the Regional Committee on Human Experimentation.

Analysis of the $\mathrm{T}$ cell repertoire was performed by means of spectratyping, a PCR-based technique which allows to assess CDR3 region length in the TCR families. The CDR3 region is unique for a given $\mathrm{T}$ cell and consequently all cells bearing a particular CDR3 will belong to that clone. Due to an allelic exclusion phenomenon, only a TCR-BV gene is predictively rearranged in each $\mathrm{T}$ cell. Therefore, according to TCR-BV gene, modification of specific clonotypes can be monitored both in vivo and in vitro. With this technique, a TCR family is graphically described by a series of peaks with Gaussian distribution. Alteration of intensity and/or distribution of the peaks indicates a perturbation of the $\mathrm{T}$ cell repertoire. Extended peaks are directly sequenced in order to assess the clonotype composition of each peak [21].

\section{Results}

The three patients were Caucasian females, two of them were smokers. $\mathrm{CD}$ has been diagnosed at a mean age of 23 years and histologically confirmed in all patients. CD was ileal in 2 patients and colic in one; it was stricturing in all three. Perianal fistulas have occurred at a mean age of 26.3 years. In two cases, the fistula was recurrent, trans-sphincteric in two patients and anovaginal in one. HS was diagnosed with a mean of 10.7 years after CD diagnosis. All patients have been medically treated for $\mathrm{CD}$ with cycles of steroids and mesalamine, whilst two patients have been also treated with azatioprine and infliximab for a mean of 7 and 8 months, respectively. In all cases immunosuppressive treatment has been suspended one month prior to surgery. The HS lesions were LC1 and Hurley stage II $[22,23]$ in all patients and were localized at the axilla in 2 cases and at the right 
inguinal region in the remaining case. Table 2 summarizes clinical features of the recruited patients.

Histological examination reveals florid inflammatory granulation tissue in perianal CD (Figure 1), and marked inflammatory infiltrate in apocrine glands as well as adjacent connective tissue in HS, the CD4+ T cells representing the predominant subtype in this latter (Figure 2).

MNCs have been isolated from peripheral blood (PB) samples, fistula curettage and HS lesions, and analyzed for surface marker expression and for the ability to produce IL-17 and IFN- $\gamma$ after polyclonal stimulation. In particular, due to the low number of cells recovered from fistula curettage, analysis of surface markers and intracellular cytokines was possible in all three patients only on PB- and HS lesion-derived cells. The expression of the Th1 associated molecule CXCR3 was significantly lower in HS-derived CD4+ T lymphocytes than in the PB-derived ones. On the contrary, the expression of the Th17 associated molecule CD161 was significantly higher in HS lesion-derived CD4+ T lymphocytes than in those obtained from PB (Figure 3A). Accordingly, CD4+ T lymphocytes producing IFN- $\gamma$ were more abundant in $\mathrm{PB}$ than in HS lesions, whereas CD4+ T cells producing IL-17 were more abundant in HS lesions than in PB (Figure 3B and $C$ ). In the only case in which we had the possibility to analyze the three different sources (PB, HS lesion, and fistula curretage), we found more CD4+ IL-17- producing cells in HS lesion and fistula lesion than in PB, even if the $\mathrm{CD} 4+\mathrm{IFN}-\gamma$ - producing cells did not differ among the different sources (Figure 3C). It is noteworthy that CD4+ $\mathrm{T}$ lymphocytes derived from $\mathrm{PB}, \mathrm{HS}$ and fistula, in the same patient, exhibited a similar TCRVB distribution suggesting an expansion of the same clonotypes (Figure 3D).

After a follow-up of 24 months one patient had no evidence of disease (patient number 3), whereas in the remaining two patients the HS lesion recurred after 13.2 (patient number 1) and 16.4 months (patient number 2) respectively.

\section{Discussion}

The primum movens of HS seems to be related to the occlusion of the hair follicles by keratinous plugging followed by their dilatation and disruption. Secondary bacterial infection of the apocrine glands may result in abscess formation, gland rupture, inflammation and fistula forming. Long-standing HS in the anogenital region has been suggested to precede squamous cell carcinoma [24]. The present study describes the co-morbidity of perianal $\mathrm{CD}$ and $\mathrm{HS}$ found in three patients. The association between HS and CD has recently been reinforced in nine case reports and two retrospective studies [5-16]. On interviewing $102 \mathrm{CD}$ patients, Van der Zee et al. found a history of recurrent painful boils in the axillae and/or groins compatible with HS in $17 \%$ of cases [15]. Church et al. reviewed hospital records of $61 \mathrm{HS}$ patients and observed that in 24 had also been diagnosed for CD [10]. Anal localization of HS may clinically overlap perianal $C D$ with suppurative complications leading to misinterpretation. Noteworthy, HS can arise either before or after $\mathrm{CD}$. In the latest report, $\mathrm{CD}$ diagnosis predated that of HS by an average of 3.5 years [10]. In line with these data, in our patients the diagnosis of $\mathrm{HS}$ followed that of CD.

Even if performed on a low number of patients, the present study is the first to compare the inflammatory scenario of both perianal CD fistulas and HS lesions. We documented the accumulation of CD161+ T lymphocytes, that are well known to be enriched in the Th17, Th17/Th1 and non classic Th1 phenotypes [20,21], in the $\mathrm{CD}$ fistula and HS lesion curettages. Interestingly, Th1 and Th17 lymphocytes have been claimed to play a role in CD pathogenesis [25]. The coexistence of Th1

Table 2 Clinical features of enrolled patients

\begin{tabular}{|c|c|c|c|c|c|c|c|c|}
\hline Patient & $\begin{array}{l}\text { Sex/age } \\
\text { at surgery } \\
\text { (years) }\end{array}$ & Smoker & $\begin{array}{l}\text { Age at CD } \\
\text { diagnosis } \\
\text { (years) }\end{array}$ & $\begin{array}{l}\text { Age at perianal } \\
\text { fistula diagnosis } \\
\text { (years) }\end{array}$ & $\begin{array}{l}\text { CD localization/ } \\
\text { type of perianal } \\
\text { fistula }\end{array}$ & $\begin{array}{l}\text { Age at HS } \\
\text { diagnosis } \\
\text { (years) }\end{array}$ & Type of HS & $\begin{array}{l}\text { Previous } \\
\text { therapy }\end{array}$ \\
\hline \multirow[t]{4}{*}{1} & $F / 49$ & Yes & 21 & 20 & Ileal/transsphincteric & 33 & Inguinal, recurrent & Steroid \\
\hline & & & & & & & & Mesalamine \\
\hline & & & & & & & & Azatioprine \\
\hline & & & & & & & & Infliximab \\
\hline \multirow[t]{3}{*}{2} & $F / 26$ & Yes & 22 & 26 & Colic/Ano-vaginal & 26 & Axillary & Steroid \\
\hline & & & & & & & & Mesalamine \\
\hline & & & & & & & & Adalimumab \\
\hline \multirow[t]{4}{*}{3} & $F / 42$ & No & 26 & 33 & Ileal/transsphincteric & 40 & Axillary & Steroid \\
\hline & & & & & & & & Mesalamine \\
\hline & & & & & & & & Azatioprine \\
\hline & & & & & & & & Infliximab \\
\hline
\end{tabular}




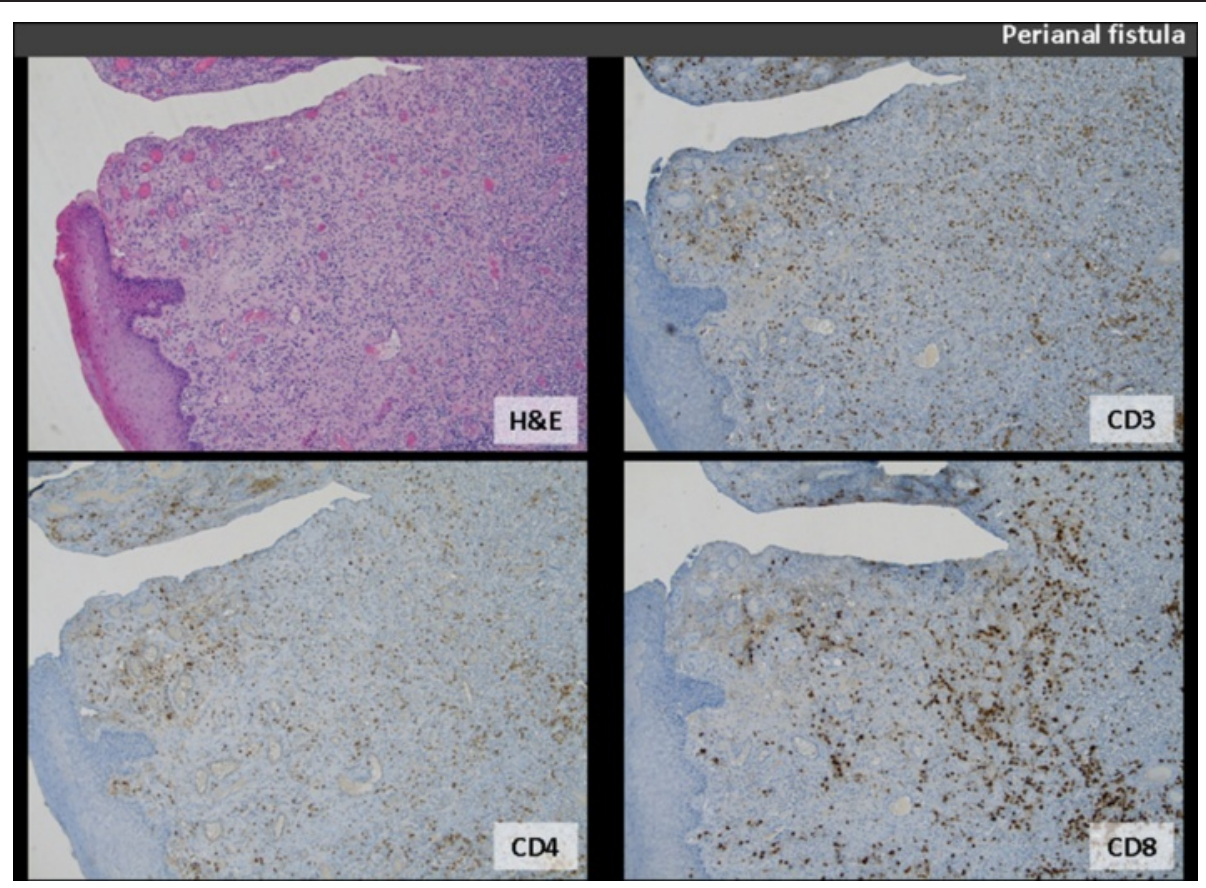

Figure 1 Perianal fistula sample: haematoxylin-eosin (H\&E) staining reveals denuded surface, overlying florid inflammatory granulation tissue (original magnification $\times 5$ ). The $C D 3+, C D 4+$ and $C D 8+T$ cells are identified by appropriate immunohistochemical stains (patient $n^{\circ} 3$ ).

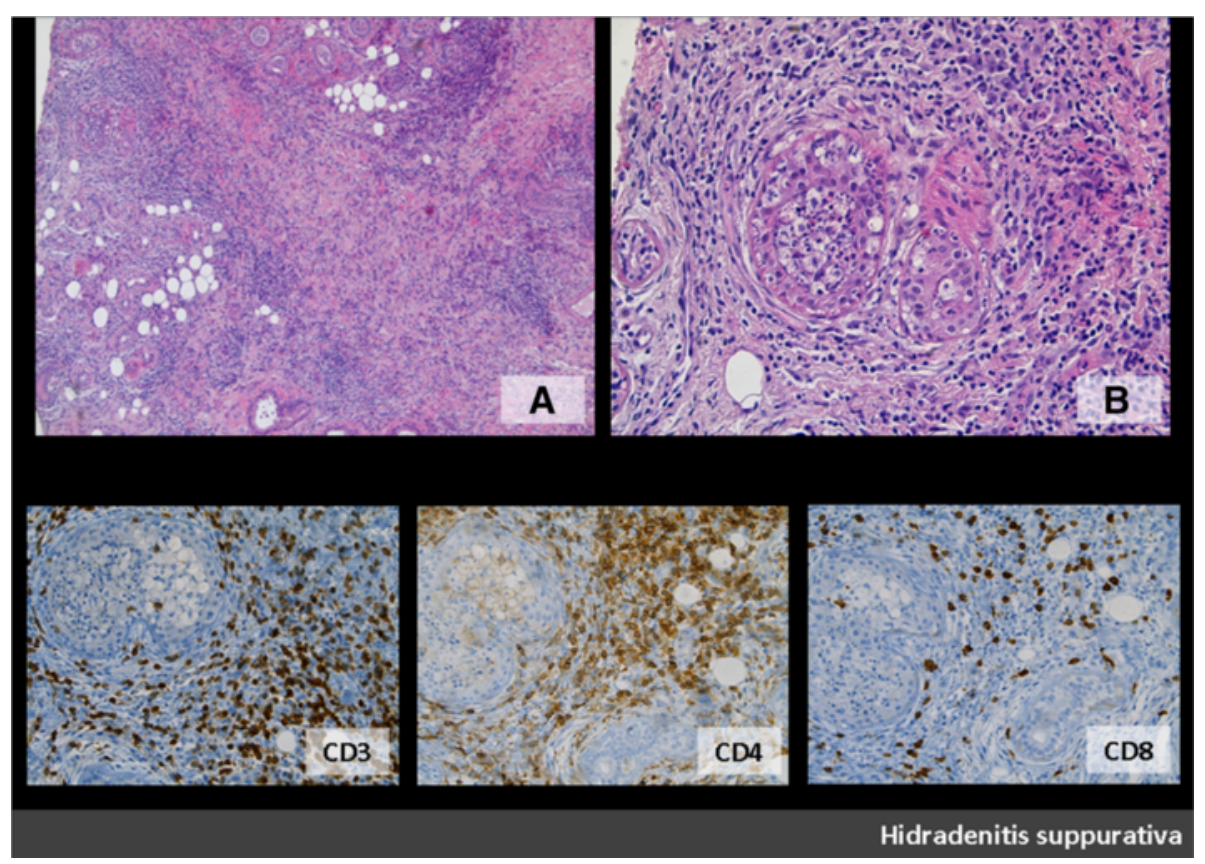

Figure 2 HS sample: in HS, marked acute and chronic inflammatory infiltrate involves apocrine glands as well as adjacent connective tissue (A: H\&E, original magnification, $\times 5$; B: H\&E, original magnification, $\times 20$ ) (patient $n^{\circ} 3$ ). Chronic inflammatory infiltrate includes $T$ lymphocytes $(C D 3+)$ with CD4+ T cells representing the predominant subtype (original magnification, $\times 20$ ). (inferior panel: CD3, CD4, CD8). 


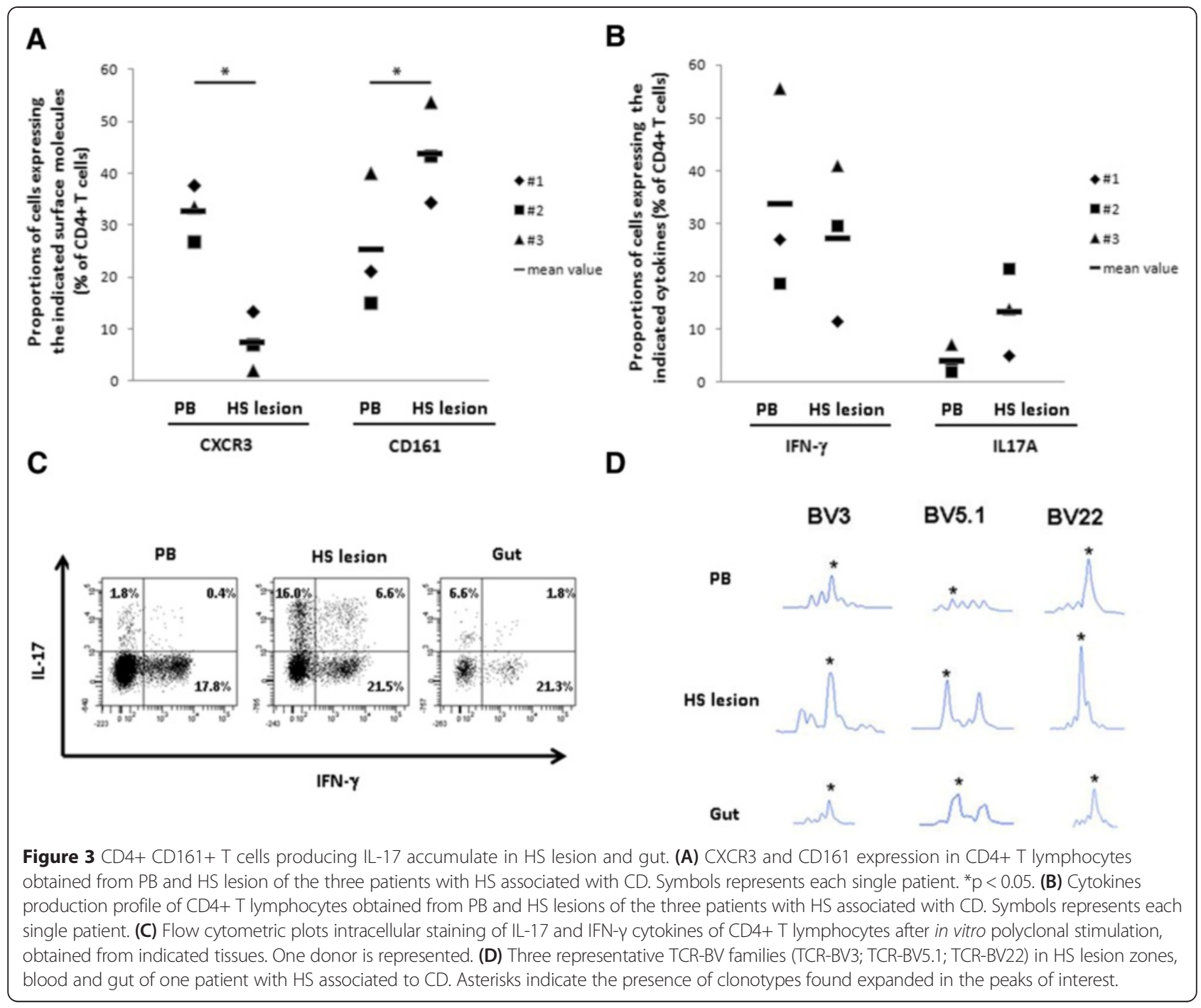

and Th17 cells in the same microenvironment and their cooperation in the pathogenesis of several inflammatory diseases have also been reported [18,21]. It has also been shown that Th17 cells can shift towards the Th1 phenotype in the presence of IL-12, through an intermediate state in which the cells are capable of producing both IL-17A and IFN- $\gamma$ (Th17/Th1 subset) [18,21]. Since IL12 is highly expressed in CD tissue samples [25], we speculate that Th17 cells could be modulated to become Th17/Th1, or even Th1, during the course of the disease. Accordingly, it has recently been suggested that Th1 and Th17 cytokines can act synergistically in the development of the disease [25]. Indeed, some reports describe the effectiveness of the anti-IL-12/23 p40 chain monoclonal antibody ustekinumab, which inhibits receptorbinding of both IL-12 and IL-23, thus blocking Th1 and Th17 differentiation, in the treatment of CD [26]. Moreover it has been recently described the involvement of
IL-23/Th17 pathway in the pathogenesis of skin hidradenitis suppurative [27].

The finding of a possible pathogenic association between $\mathrm{CD}$ and HS, could have also therapeutical implications. Indeed, treatment with biologics blocking TNF- $\alpha$ has been observed in both diseases [13,14,17], and a favourable outcome has been reported particularly in the early stages of HS. However, refractory cases to antiTNF- $\alpha$ therapy have also been described as well as patients developing HS under anti-TNF- $\alpha$ treatment [28].

Finally, here we describe a possible association between CD and HS, based on immunological analysis of infiltrating $\mathrm{T}$ cells compared to $\mathrm{PB}$; in any case additional factors could be involved in the pathogenesis of the diseases and of course additional studies are necessary to define if other molecules associated to these disease will be common to both or specific of each one [29-31]. 


\section{Conclusion}

In conclusion, this work reinforces the link between HS and $\mathrm{CD}$, providing evidence that $\mathrm{CD} 4+\mathrm{CD} 161+\mathrm{T}$ lymphocytes accumulate in perianal fistulas and HS in $\mathrm{CD}$ patients and may play a crucial role in the pathogenesis of both diseases. Potential therapeutic implications of these results need to be further investigated.

\section{Abbreviations}

CD: Crohn's disease; HS: Hidradenitis suppurativa; Th: T helper; PB: Peripheral blood; IFN: Interferon; IL: Interleukins; TNF: Tumor necrosis factor; mAbs: Monoclonal antibodies; MNCs: Mononuclear cells; PCR: Polymerase chain reaction; CDR3: Complementarity determining region 3; TCR-BV: T-cell receptor beta-chain variable.

\section{Competing interests}

The authors declare that they have no competing interests.

\section{Authors' contributions}

FG, LM, RS, GaB and GiB performed the experiments and collected the data, LC, CS, FA, GN and RDP analysed data, FG, LM, RS, GB LC, FA, GN, RDP and FT wrote the manuscript; FT and GN supervised the manuscript. FT, FA, GN gave the final approval of the version to be submitted. All authors read and approved the final manuscript.

\section{Acknowledgements}

This work was supported by grants from AIRC, MIUR, Italian Ministry of Health (RF-2010-2314610), Ministero dell'Istruzione, dell'Università e della Ricerca, PRIN 2009 (200999KRFW_003).

\section{Author details}

${ }^{1}$ Department of Surgery and Translational Medicine, University of Florence, Florence, Italy. ${ }^{2}$ Department of Experimental and Clinical Medicine, University of Florence, Florence, Italy. ${ }^{3}$ Department of Clinical and Experimental Medicine, Second University of Naples, Naples, Italy. ${ }^{4}$ Department of Medicine, University of Perugia, Perugia, Italy.

Received: 21 January 2015 Accepted: 7 April 2015

Published online: 22 July 2015

\section{References}

1. Revuz J. Hidradenitis suppurativa. J Eur Acad Dermatol Venereol. 2009;23:985-98

2. Abraham C, Cho JH. Inflammatory bowel disease. N Engl J Med. 2009:361:2066-78. 3.

3. Fielding JF. Perianal lesions in Crohn's disease. J R Coll Surg Edinb. 1972:17:32-7.

4. Tonelli F, Giudici F, Asteria CR. Effectiveness and safety of local adalimumab injection in patients with fistulizing perianal crohn's disease: a pilot study. Dis Colon Rectum. 2012;55:870-5.

5. Ostlere LS, Langtry JA, Mortimer PS, Staughton RC. Hidradenitis suppurativa in Crohn's disease. Br J Dermatol. 1991;125:384-6.

6. Gower-Rousseau C, Maunoury V, Colombel JF, Coulom P, Piette F, Cortot A, et al. Hidradenitis suppurativa and Crohn's disease in two families: a significant association? Am J Gastroenterol. 1992;87:928.

7. Burrows NP, Jones RR. Crohn's disease in association with hidradenitis suppurativa. Br J Dermatol. 1992;126:523.

8. Attanoos RL, Appleton MA, Hughes LE, Ansell ID, Douglas-Jones AG, Williams GT. Granulomatous hidradenitis suppurativa and cutaneous Crohn's disease. Histopathology. 1993;23:111-5.

9. Kafity AA, Pellegrini AE, Fromkes JJ. Metastatic Crohn's disease. A rare cutaneous manifestation. J Clin Gastroenterol. 1993;17:300-3.

10. Church JM, Fazio WW, Lavery IC, Oakley JR, Milsom JW. The differential diagnosis and comorbidity of hidradenitis suppurativa and perianal Crohn's disease. Int J Colorectal Dis. 1993:8:117-9.

11. Tsianos EV, Dalekos GN, Tzermias C, Merkouropoulos M, Hatzis J. Hidradenitis suppurativa in Crohn's disease. A further support to this association. J Clin Gastroenterol. 1995;20:151-3.
12. Roy MK, Appleton MA, Delicata RJ, Sharma AK, Williams GT, Carey PD. Probable association between hidradenitis suppurativa and Crohn's disease: significance of epithelioid granuloma. Br J Surg. 1997;84:375-6.

13. Martinez F, Nos P, Benlloch S, Ponce J. Hidradenitis suppurativa and Crohn's disease: response to treatment with infliximab. Inflamm Bowel Dis. 2001;7:323-6.

14. Roussomoustakaki M, Dimoulios P, Chatzicostas C, Kritikos HD, Romanos J, Panayiotides JG, et al. Hidradenitis suppurativa associated with Crohn's disease and spondyloarthropathy: response to anti-TNF therapy. J Gastroenterol. 2003;38:1000-4.

15. Van der Zee HH, van der Woude CJ, Florencia EF, Prens EP. Hidradenitis suppurativa and inflammatory bowel disease: are they associated? Results of a pilot study. Br J Dermatol. 2010;162:195-7.

16. Yazdanyar S, Miller IM, Jemec GB. Hidradenitis suppurativa and Crohn's disease: two cases that support an association. Acta Dermatovenerol Alp Panonica Adriat. 2010;19:23-5.

17. Jemec GB, Revuz J, Leyden J. Hidradenitis suppurativa. 1st ed. Heidelberg: Springer; 2006

18. Annunziato F, Cosmi L, Santarlasci V, Maggi L, Liotta F, Mazzinghi B, et al. Phenotypic and functional features of human Th17 cells. J Exp Med. 2007:204:1849-61.

19. Romagnani P, Annunziato F, Baccari MC, Parronchi P. T cells and cytokines in Crohn's disease. Curr Opin Immunol. 1997;9:793-9.

20. Maggi L, Capone M, Giudici F, Santarlasci V, Querci V, Liotta F, et al. CD4+ CD161+ T lymphocytes infiltrate Crohn's disease-associated perianal fistulas and are reduced by anti-TNF-a local therapy. Int Arch Allergy Immunol. 2012;161:81-6.

21. Cosmi L, Cimaz R, Maggi L, Santarlasci V, Capone M, Borriello F, et al. Evidence of the transient nature of the Th17 phenotype of CD4+ CD161+ $T$ cells in the synovial fluid of patients with juvenile idiopathic arthritis. Arthritis Rheum. 2011;63:2504-15.

22. Canoui-Poitrine F, Le Thuaut A, Revuz JE, Viallette C, Gabison G, Poli F, et al. Identification of three hidradenitis suppurativa phenotypes: latent class analysis of a cross-sectional study. J Invest Dermatol. 2013;133:1506-11.

23. Hurley $\mathrm{H}$. Axillary hyperhidrosis, apocrine bromhidrosis, hidradenitis suppurativa, and familial benign pemphigus: surgical approach. In: Roenigk RK, Roenigk HH, editors. Roenigk and Roenigk's dermatologic surgery: principles and practice. New York: Marcel Dekker; 1989. p. 623-45.

24. Slade DE, Powell BW, Mortimer PS. Hidradenitis suppurativa: pathogenesis and management. Br J Plast Surg. 2003;56:451-61.

25. Strober W, Fuss IJ. Proinflammatory cytokines in the pathogenesis of inflammatory bowel diseases. Gastroenterology. 2011;140:1756-67.

26. Sandborn WJ, Feagan BG, Fedorak RN, Scherl E, Fleisher MR, Katz S, et al. A randomized trial of ustekinumab, a human interleukin-12/23 monoclona antibody, in patients with moderateto-severe Crohn's disease. Gastroenterology. 2008;135:1130-41.

27. Schlapbach C, Hänni T, Yawalkar N, Hunger RE. Expression of the IL-23/Th17 pathway in lesions of hidradenitis suppurativa. J Am Acad Dermatol. 2011;65:790-8

28. Koilakou S, Karapiperis D, Tzathas C. A case of hidradenitis suppurativa refractory to anti-TNFalpha therapy in a patient with Crohn's disease. Am J Gastroenterol. 2010;105:231-2.

29. Matusiak $Ł$, Salomon J, Nowicka-Suszko D, Bieniek A, Szepietowski JC. Chitinase-3-like Protein 1 (YKL-40): Novel Biomarker of Hidradenitis Suppurativa Disease Activity? Acta Derm Venereol. 2015. doi:10.2340/00015555-2061.

30. Nassar D, Hugot JP, Wolkenstein P, Revuz J. Lack of association between CARD15 gene polymorphisms and hidradenitis suppurativa: a pilot study. Dermatology. 2007;215(4):359.

31. Frew JW, Vekic DA, Woods J, Cains GD. Phenotypic heterogeneity implies heterogeneous pathogenic pathways in Hidradenitis Suppurativa. Exp Dermatol. 2015. doi:10.1111/exd.12648. 